\title{
Urticaria as Symptom of Parasite Migration Through the Biological Barriers
}

\author{
Alketa Hysni Bakiri ${ }^{1}$, Ervin Çerçiz Mingomataj ${ }^{1,2, *, \dagger}$ \\ ${ }^{1}$ University of Tirana, Nursing Faculty, Dept. of Preclinical Disciplines - Albania \\ ${ }^{2}$ Mother Theresa” School of Medicine, Dept. of Allergology \& Clinical Immunology, Tirana - Albania
}

\begin{abstract}
The absence of a consistent link between parasitoses and urticarial symptoms in the clinical investigations contrasts to the fact that some parasites are the most potent inducers of immunoglobulin $\mathrm{E}$ that exist in nature. To shed some light into this question, this review is focused on the actual knowledge regarding parasites life cycle, interactions with host immunity, the influence on host behavior, and finally the role of all these factors on the urticaria development. The collected data demonstrate that parasites could manipulate the host behavior for its own benefit in different ways, inducing urticarial reactions during penetration into different biological barriers. In this context, urticaria may be associated with certain stages of the parasites' life cycle or with host tissue location, but not necessarily only with their presence in the host organism. As compared to T helper (Th) 1, the Th2 response, the eosinophilic infiltration and the complement inhibition could assure a more pleasant surrounding area for the development of some parasites. Taken together, these concepts could explain the epidemiological discrepancy between low rates of urticaria occurrence, and the usual parasites-induced Th2 response. However, further studies are necessary to provide better-based conclusions.
\end{abstract}

Key Words: Eosinophil attraction, host behavior, parasites life cycle, urticaria, Th1/Th2 response.

\section{INTRODUCTION}

Parasitic diseases are considered as potential cause of urticaria [1-3]. Nevertheless, laboratory and clinical investigations greatly vary from one centre to the other. Thus, a high prevalence of Toxocara canis markers in chronic urticaria is not associated with constant effects during the anti-parasitic treatment [4]. Similarly to this, Giardia lamblia is reported to be an urticaria-inducer only in a few case reports [5-7]. However, some authors consider the urticaria a secondary symptom of the gastrointestinal infection due to its cysts and trophozoite forms, as they may disappear under specific treatment [7]. Also, the presence of urticaria associated with Blastocystic hominis infection has been described only in casuistic studies $[8,9]$.

The absence of a consistent link between parasitoses and skin allergic symptoms in the clinical investigations contrasts to the fact that some parasites are possibly the most potent inducers of immunoglobulin (Ig) $\mathrm{E}$ that exist in nature [10-14]. In effect, the immuno-inflammatory response to helminthic infections and allergic pathologies have some similarities, the most profound being the increases in eosinophils and serum total IgE concentration [10-13, 15, 16]. Both entities - helminthic infections and atopic response are Th2/interleukin (IL)-4 inducers, but helminthic infections do not only stimulate specific IgE responses against their own antigens, but also they may induce a strong non-specific polyclonal synthesis of this Ig [10-14].

*Address correspondence to this author at the Rruga Myslym Shyri, P. 47, Apt. 15, Tirana - Albania; Tel: ++35542427010; Fax: ++35542229203; E-mail: allergology@gmx.de

${ }^{\dagger}$ Both authors contributed equally to this work.
Irrespective of the abundant literature regarding the association between exposure to parasites and the enhancement of $\mathrm{IgE}$ response, no definite conclusions about the causality of the weak association between these findings and the low frequency of urticarial reactions are yet warranted. To shed some light into this question, this review is focused on the actual knowledge about parasites life cycle, interactions with host immunity, influence on host behavior as well as the role of these factors on the urticaria development.

\section{HOST-PARASITE INTERACTION AND PARASITO- SIS-URTICARIA RELATIONSHIP}

Parasites are designed by evolution to invade the host and survive in its organism until they are ready to reproduce [17]. They can release a variety of molecules that help them to penetrate the defensive barriers and avoid the host immune attack. Thus, while various hostile or parasitic proteinases are involved in tissue invasion and extracellular protein digestion, helminths secrete also serpins, aspins, and cystatins to inhibit these enzymes. These mediators, as well as helminth cytokines homologues can influence the immune response of the host, biasing it towards the Th2 type [11-13, 17]. The IgE response as component of the Th2 profile, together with eosinophilic infiltration, is assumed to be a cornerstone of host defense during parasitoses [10-14, 18].

Meanwhile, current reports suggest that interaction between parasites and hostile immunity is more complex than previously estimated. In nematodes, the Th2 type response is affected by parasitic challenge [18]. For Trichiuris muris infections, Th1-type immune responses occurred in animals given repeated low parasite burden infections; latterly, the immune response developed into a protective Th2-type re- 
sponse. During Strongyloides ratti infections, the host immune response changes both qualitatively from a Th1- to a Th2-type immune response and the Th2-type response increases quantitatively with higher parasite burden infections [18].

In contrast to the IgE, the parasitic survivorship was significantly negatively related to the concentration of parasitespecific $\operatorname{IgG} 1$ and $\operatorname{IgA}[19,20]$. At the metacestode stage of Echinococcus infection, studies of the immune responses in the experimental murine model as well as in humans have shown that cellular immunity induced by a Th1-type cytokine secretion was able to successfully kill the metacestode at the initial stages of development, whereas antigenic proteins and carbohydrates of the oncosphere/metacestode were able to interfere with antigen presentation and cell activation [21]. This leads to the production of IL-10 and other mediators by host lymphocytes and other immune cells, and therefore, to the inhibition of the effector phase of cellular immune reaction [21].

With respect to anisakiasis, acute symptoms are caused by an IgE-mediated allergic reaction in the gastrointestinal wall. Similarly to this pathology, the majority of chronic patients with schistosomosis presented a Th2 profile with low production of gamma interferon (IFN- $\gamma$ ) as compared to subjects resistant to this infection, while the IL-10 production depends on the infection intensity [22]. In addition, the blockade of IL-4 and IL-5 as well as the addition of the recombinant IL-10 significantly reduced the peripheral blood mononuclear cell proliferative response to soluble egg and adult worm antigens [23]. In addition, experiments in mice have shown that the relative success of Giardia muris in completing its life cycle in a primary infection might be due, in part, to the stimulation of a Th2-type response. In contrast, a stronger Th1 response may lead to a better control of the infection [24]. These data suggest that IL-10 is an important cytokine in regulating the immune response and possibly controlling morbidity in human parasitoses, while the IFN- $\gamma$ production may be associated with resistance to infection [23]. However, increased IL-10 and IgG4 plasma concentration have been also reported in hypo-responsive and asymptomatic cases of helminth infection, such as human filaria [25].

These findings may suggest that hostile IgE/Th2 response has defensive effects, but the $\mathrm{IgG} / \mathrm{Th} 1$ subtype may also provide such qualities, which in some situations seem to be superior to the Th2 phenotype. In vivo, the Th2 profile might be not simply a host-chosen reaction, but rather the most efficient permitted humoral response during hostparasite interaction. The fatal outcome in apparently immunocompetent patients due to multiorgan failure after Strongyloides stercoralis septicaemia following a short course of prednisolone therapy could lead to the additional suggestion that glucocorticoids may suppress the parasiteattenuated host immune defenses [26].

The afore-mentioned data may indicate that even hostile cytokines used for cell-cell communication can also be exploited by the parasite as clues to find suitable target organs [27]. We share the opinion that Th2 deviation may permit parasites to invade the host organism, and to select specific organs or host cell types as predilection site to reside, matu- rate or even proliferate $[11,28,29]$. While many microparasites escape immune attack by antigenic variation or sequestration in specialized niches, helminths appear to thrive in exposed extracellular locations, such as the lymphatics, bloodstream, or gastrointestinal tract [29, 30]. Key events among the host cell population are dominance of the $\mathrm{Th} 2$ cell phenotype and the selective loss of effector activity against a background of regulatory $\mathrm{T}$ cells, alternatively activated macrophages, and Th2-inducing dendritic cells. The sum effect of these changes to host reactivity is to create an environment, which is most favorable to parasite survival [30]. In Echinococcus multilocularis infection, a combined Th1 and Th2 cytokine profile appears crucial for prolonged metacestode growth and survival. Vuitton has demonstrated that Th1 cytokines promote the initial cell recruitment around the metacestode and are involved in the chronicity of the cell infiltrate leading to a fully organized periparasitic granuloma and its consequences, fibrosis and necrosis [21]. Meanwhile, the Th2 cytokines could be responsible for the inhibition of a successful parasite killing, especially because of the immuno-modulatory potency of IL-10. This combination of various arms of the immune response results in a partial protection of both Echinococcus metacestode and host $[21,31]$. However, it may also be considered responsible for several disease complications. The Th2-related IgE synthesis and mast cell activation are more rarely involved in "allergic" complications of alveolar echinococcosis [21]. With respect to Anisakis simplex, it shares several epitopes with IL-4, important for the Th2 response development in human anisakiasis, where the parasite may modulate the Th1-Th2 dichotomy for its own benefit by mucosal inflammation control in an attempt to avoid the larval expelling [32].

Apart from the increasing of the tissue permeability and larvae penetration, the induction of $\mathrm{IgE}$ response could have an additional effect in the development of parasites within the hostile organism. In contrast to $\operatorname{IgG}$, the $\operatorname{IgE}$ antibody does not activate the complement system. In animal experiments, IgG is shown to activate complement, and therefore, to kill the L3 larvae of Angiostrongylus cantonensis [33]. In vivo, however, the classic pathway activation can be avoided because IgE does not interact with $\mathrm{C} 1$ fraction of the complement [34]. Regarding the complement inhibition in humans, the larval L3 products of anisakis exercised a stronger effect on the classical pathway than on the alternative one, constituting a mechanism to evade host defenses, similarly to other parasitic diseases. Detailed studies revealed that larval products of Anisakis simplex act at the level of the C3 and C2 proteins, which are early components of the classical complement pathway $[35,36]$. In contrast, the asymptomatic infections of human lymphatic filariasis and onchocerciasis are characterized by high plasma concentrations of $\mathrm{IgG} 4$ (compared with those of $\operatorname{IgE}$ ) and of the complement-fixing antibodies $\operatorname{IgG} 1, \operatorname{IgG} 2$ and $\operatorname{IgG} 3$ [25]. Notably, elevations in IgG4 are also often associated with high worm loads [25]. These findings indicate that parasites cannot "switch off" the humoral host immunity, but they could induce the Th2 profile, or at least the IgG4 production. The Th2/IgE or IgG4 responses may assure better survival possibilities for the parasites within the host due to parasitic avoidance of the complement system activation. 
Apart from parasitoses, the $\operatorname{IgE}$ response is also strongly associated with pathogenesis of the immediate allergic diseases such as urticaria, angioedema, etc. Despite expectations, the association of the urticarial reactions with presence of parasitic infections does not agree with epidemiological data [4]. Recently, much evidence is collected about the interaction's details between the hosts and parasites, but fewer attempts are made to clarify the urticarial puzzle during parasitoses. Reflecting on these findings, it could be mentioned that urticaria is a skin manifestation, related to helminths or arthropods with a cutaneous phase: Schistosoma, Sarcoptes scabiei, as well as ticks and other blood sucking arthropods have been involved in Th2-based immunologic mechanisms $[37,38]$. Among patients with toxocariasis, an elevated eosinophil cationic protein (ECP) level was significantly associated with both cough and rhinitis, a high level of specific anti-toxocara IgE with itchy rashes [39]. Loeffler's syndrome, which resembles the pathophysiological features of chronic asthma with its Th2-related immunologic feature, is related to Ascaris and Necator infection, both of which have an obligatory pulmonary phase [40]. Some helminths like Necator and Schistosoma have even both a cutaneous and pulmonary phase [41]. Such pathologies as larva migrans or cercarial dermatitis are also examples of the skin migration. Being attempts to find the suitable host environment, the parasitic induction of urticaria, atopic phenotype, itching and the increased tissue permeability could favorise larvae migration and therefore, the completing of the parasitic life cycle $[11,14]$. In the case of human anisakiasis, this would be a hopeless attempt to destroy hostile barriers (intestinal wall, etc) to search for the missed suitable environment, because they cannot develop within terrestrial mammalians. Consequently, the type I allergic reaction takes at least 2 to 6 hours to be triggered by alive larvae, while the ingestion of lyophilized larvae, or its equivalent in antigen, does not induce clinical symptoms in sensitized individuals [42, 43]. A similar scenario develops also within paratenic hosts during larvae migration in different visceral organs, like in case of Toxocara canis [44]. These data suggest that the development of allergic symptoms could be an active effect of parasites and not only a host defense reaction.

In some particular cases, $\operatorname{IgE}$ and $\operatorname{IgG}$ values will differ depending on the time relapsed between the parasitic contact and therefore on its developing phase [45]. During infection of mice with Litomosoides sigmodontis, female adult worms from prepatent infections protects mice injected with lipopolysaccharide due to inhibition of the host Th1 response, whereas microfilariae worsen lipopolysaccharideinduced sepsis through the induction of the Th1-related cytokines in the peripheral blood [28]. Similarly to the immune modulation, Giardia lamblia can express different kinds of variant surface proteins (VSP). The giardial varianttype formation and VSP mRNA levels after infection of mice with cysts lead to an antigenic reset of the parasite, which appears to be associated with excystation [46]. In this respect, the VSP H7 type has to be regarded as a predominant variant of Giardia lamblia clone GS/M-83-H7 that emerges during early-stage infection and may contribute to an optimal establishment of the parasite within the intestine of the experimental murine host [46]. In summary, the Th2 response seems to be a host reaction, induced under the parasites' in- fluence. It may permit the migration of parasites under the skin, in lymphatic ways and into some parenchimatous organs. In a few cases, this response may be induced in some developing phases, such as in case of excystation (also a kind of barrier penetration), or Giardia inoculation in the enteric epithelium. These data indicate that urticarial symptoms may be related to the larval stage or hostile tissue penetration, but not necessarily only to the presence of parasitic infection in the hostile organism. This may explain the lack of clear evidence regarding the correlation between the parasitic diseases and the urticaria development.

In spite of the humoral mechanisms, there is evidence of important parasite-induced effects on innate cell types, particularly mast cells and eosinophils. According to Maizels et al., the sum effect of these changes to host reactivity is to create an "anti-inflammatory environment", which is most favorable to parasite survival $[13,30]$. However in our opinion, the role of eosinophils is more complex. The eosinophils like the complement system can induce increased cell membrane permeability $[47,48]$. This eosinophil-induced role is also shown on various biologic barriers, including the parasite surfaces, and it is called "frustrated phagocytosis" $[46,49]$. Thus, Kaji et al. reported about an urticarial reaction, eosinophilic cholecystitis and a simultaneous onset with pericarditis after an Ascaris infection [50]. Meanwhile, infection from Angiostrongylus cantonensis is generally associated with damage of blood-brain barrier and neurological disorders, which is assumed to be a consequence of eosinophilic meningitis $[48,51]$.

Besides the host-influence, eosinophils migration close to parasites could be also a strategic step induced even from the parasite, leading to the allergic symptoms. While a hypereosinophilia is an argument in favor of a progressive toxocara infection, high total $\operatorname{IgE}$ level is considered a hallmark of visceral infections by parasites [52, 53]. A study, conducted by Stein et al. demonstrated that another nematode, Strongyloides stercoralis, expresses one or more eosinophil chemoattractants, leading to the conclusion that helminths may have evolved unique mechanisms that actually exploit the LIAR-based eosinophil activities as part of their life cycle (LIAR - localized immune and remodeling/repair) [54, 55]. Anisakis larvae extract, also exercises chemotactic effect for eosinophils [56]. In this context, alive L3 larvae can exhibit the main hyperergic response in the duodenum, decelerating their transit into the successive parts of intestinum, but also inducing the transit into the tissues outside the duodenal lumen [57]. In other words, since parasites affect the behavior traits with selectively benefit the parasite, rather than causing a general alteration of the host behavior, the induction of the urticaria might be only a sign of efficient or hopeless larval attempt to find the suitable host to produce eggs. The IgE-response, the eosinophilic chemotaxis, or the general itching cannot be only host defenses, but also larval attempts to destroy hostile barriers to search for the missed suitable hostile environments. Taken together, these findings indicate that eosinophils as biological barrier perforators are implicated under the simultaneous influence of the host and parasites in a double game. This hypothesis is supported for example by the presence of local eosinophil infiltration in the skin when Dracunculus medinensis larvae emerge from the inferior limbs in the 
ponds water [58]. In these circumstances, the eosinophils could help parasites to destroy the skin integrity, because in this stage dracunculae larvae can be developed only within thermocyclops living in ponds. This also demonstrates that helminths display highly complex life cycles, in which the establishment of adults or larvae within hostile target organs as well as the transition of a developmental stage to the successive one is influenced by host-derived factors [27].

The parasite-manipulated involvement of host immune mechanisms supports the opinion that parasites can be efficient manipulators of the host behavior [57]. The parasitic ability to affect the behavior of infected host has been documented by different authors [11-14, 59, 60]. Although changes in the behavior of infected hosts do occur for pathogens with direct life cycle, they are most commonly recorded in the intermediate hosts of parasites with complex life cycle. In this case, because sexual reproduction of Toxoplasma gondii can be accomplished only in felines, there are strong selective pressures on the parasite to evolve mechanisms to enhance transmission from the intermediate host to the definitive feline one, and thereby complete its life cycle [61, 62]. The predilection of this protozoon for the brain of its intermediate host places it in a privileged position to cause such manipulation [62]. Ferreira et al. recently demonstrated that the host cell transcriptome, including the expression of distinct host cell genes, can trigger bradyzoite development and cyst formation, indicating that the complex cellular environment may govern the developmental differentiation of this protozoon [63]. Moreover, the pattern of histone H3 arginine methylation distinguishes certain promoters, illustrating the complexity of the histone modification machinery in toxoplasmosis $[64,65]$. Being placed in the intermediate host brain, the toxoplasma-expressed epigenomic mechanisms may lead to variations in gene expression during the transformation of tachisoites into bradysoite, waiting then for the definitive host. This way, Toxoplasma gondii dispose the ability to manipulate the personality profile of the intermediate host $[14,59]$. The toxoplasma-infected people are more predisposed to take a risk, or are less watchful for example in the motorways, whereas toxoplasmosis-infected rats can even lose the cat predation risk [14, 61, 66, 67]. The loss of predation risk by rats or the loss of watchfulness by humans at least at the prehistoric time before the invention of entombment, after a toxoplasmic infection, led usually to the rip of their bodies from some carnivore and therefore to the transmission of the parasite into its definitive host like felines [14]. This parasite, thus manipulates the behavior of its intermediate host to enhance its transmission to the definitive one $[66,67]$. In a similar manner, the experimentally Toxocara canis-infected BALB/c mice take significantly longer to drink from a water source compared with control mice [68]. Moreover, infected mice displayed reduced levels of anxiety to aversive and exposed areas of the maze, particularly in the case of the moderate and high intensity mice [69]. These findings lead to the suggestion that a Toxocarainfected paratenic host can be an easier prey for their predators. During dracunculiasis, the burning effect in patient's lower limbs during pregnant larvae extrusion is also a host behavior manipulation, because the expelling first-stage larvae can be developed only within copepods of the ponds
[58]. Consequently, the patient hurries to immerse the burning limbs in the ponds in order to cool them.

The reduction of respiratory allergic symptoms (like wheezing or airway hyperreactivity) in intensive helminthinfected populations is another example of host behavior manipulation and an evolutionary adaptation from the point of view of parasites [14]. This reduction assures those better chances for their reproduction and development in the environment "host", because the liberation mammalian efforts against these parasites are suppressed. Thus, Toxocara, Ascaris, Trichiuris, and hookworm have a phase of larval migration into the respiratory system or at least, their entrance way (as eggs) in the human body is the nose or the mouth $[14,40]$. To assure their penetration into the host and latter their reproduction or development, these parasites need to affront or avoid the reactive (including allergic) response of the host (like the cough, airway obstruction and airway hyper-responsiveness) due to induction of immuno-modulatory network [11-14, 70].

\section{CONCLUSIONS}

Based on the current knowledge, it could be concluded that parasites attempt to manipulate the host behavior for its own benefit in different ways, altering its (epi)genetic, biochemical, immunologic or physiologic functions as well as altering its behavior and activity $[11-14,42,43,62,65,71$, 72]. Both protozoan and cestode/nematode parasites may induce the Th1/Th2 switch in order to assure better possibilities to survive in the hostile organisms, but among them helminths are the superior IgE inducers [10-14, 21, 24]. In this framework, could be postulated that the higher parasitic burden, the more efficient seems to be the parasite-related manipulation [14, 18]. Acting as immune manipulators during infection, parasitic allergens and their cytokines can induce the IgE synthesis or at least the IgG4 one, to avoid the antiparasitic role of complement system [14, 25, 34-36]. On the other hand, urticaria induction due to IgE-mediated mast cell degranulation seems to be an active parasitic effect that can provide the parasitic migration into tissues [42, 43, 73]. Usually, urticaria can be induced by multicellular or enteric parasites such as Anisakis simplex, larva migrans and currents, Giardia lamblia or cercarial dermatitis, but even protozoan blood parasites may induce urticarial reactions during unusual migration through a compact tissue $[5,15,16,19$ $21,32,41-43,74-77]$. Because the parasitic migration may be related to certain life cycle stages, also the parasitesrelated urticaria/dermatitis occurrence and its resolving after antiparasitic therapy could not necessarily agree with epidemiologic data $[4,38,43,44,78,79]$. Apart from the involvement of humoral mechanism such as complement system and antibody response, the active role of parasite in the urticaria-associated migration and accomplishing of life cycle can be manifested by eosinophil attraction [56, 80]. In this framework, eosinophils act not only as innate immune cells, but also as perforators of biologic barriers [47, 48]. Recent studies of the structure, content, and activities of the eosinophil have shown that it has potent toxic proteins with the potential to mediate tissue damage after its disruption $[54,80]$. Specifically, deposition of eosinophil granule proteins outside of eosinophils has been observed in pathologies associated by elevated serum IgE levels, such as in urticarial 


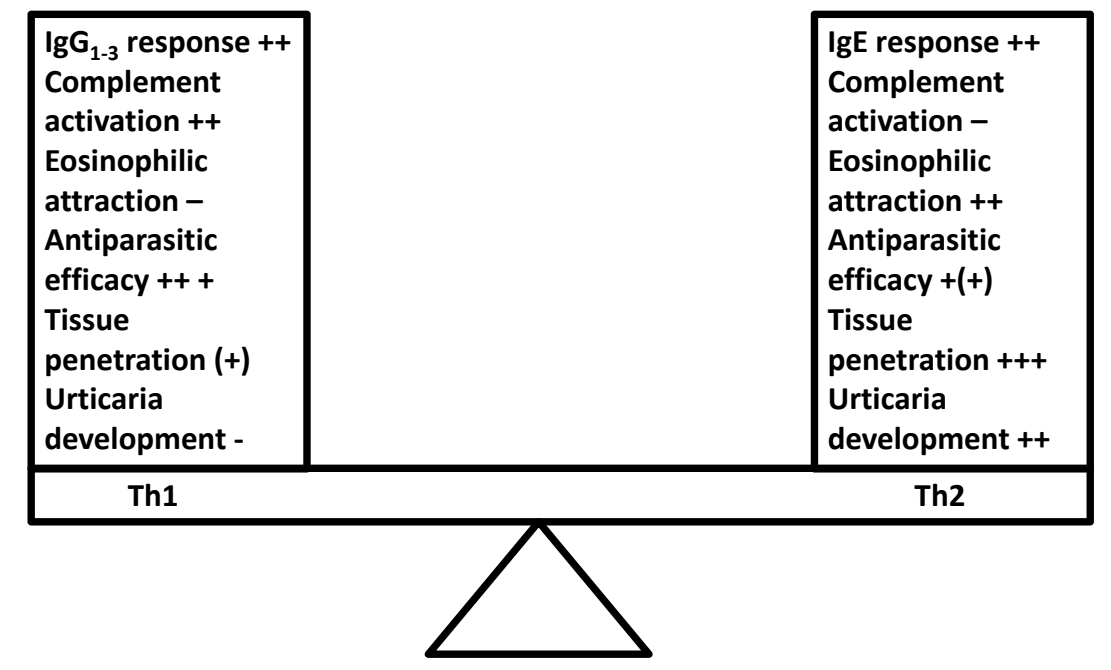

Fig. (1). Th1 vs. Th2 response during parasitoses and the urticaria development: Although both responses provide antiparasitic effects, the Th1 seems to be superior to the Th2 response. Maybe the Th2 (and urticaria) induction is a host-response, chosen by the parasite that is associated with better survival and hostile tissue dispersion/penetration. The eosinophil chemotaxis and the avoidance of complement-dependent mechanisms are also targets of parasite-induced host immune modulation that can improve its development and survival possibilities within hostile organism.

and angioedematous disorders [80]. The tissue penetration is preceded by parasitic induction of different molecules that mediate its adherence with hostile cellular barriers. Thus, the specific IgE response during Giardia-related urticaria is also associated with expression of soluble adhesion molecules in the hostile serum, such as intercellular or vascular adhesion molecules ICAM-1 and VCAM-1, as well as IL-6 [77, 81]. Therefore, this symptom seems to be related with enteric epithelial inoculation of the parasite, but not to the enteric lumenal presence.

In summary, these findings indicate that skin allergy may be associated with certain stages of the parasites' life cycle or with host tissue location, but not necessarily only with parasites presence in the hostile organism. As compared to Th1, the Th2 response (including the IgE production), the eosinophilic infiltration and the complement inhibition could assure better conditions for the development of some parasites (see the Fig. 1) [21, 24, 35, 41, 56]. The ambiguity of the host immune response during parasitoses remains a puzzle, but much evidence stresses the fact that the sum effect of the deviated host reactivity could be the creation of a favorable environment for the parasite migration and survival within hostile organism [30]. The combination of these suggestions could be a plausible explanation for the epidemiological association's paradox between low rate of urticaria development and frequent IgE response during parasitoses [7]. In this context, the timing of urticaria occurrence seems to rely with parasites-induced tissue migration and the penetration of hostile biologic barriers. Nevertheless, further studies focused on the monitoring of experimental parasitic development, on dispersion/penetration through the host tissue, and on the association of parasitic life stages with urticarial development are necessary.

\section{REFERENCES}

[1] Ronellenfitsch U, Bircher A, Hatz C, Blum J. Parasites as a cause of urticaria. Helminths and protozoa as triggers of hives? Hautarzt 2007; 58(2): 133-4.

[2] De Gentile L, Grandiere-Perez L, Chabasse D. Urticaria and Parasites. Allerg Immunol (Paris) 1999; 31(8): 288-91.
[3] Pasqui AL, Savini E, Saletti M, Guzzo C, Puccetti L, Auteri A. Chronic urticaria and blastocystis hominis infection: a case report. Eur Rev Med Pharmacol Sci 2004; 8(3): 117-20.

[4] Cribier B, Noacco G. Chronic urticaria and infectious diseases. Ann Dermatol Venerol 2003; 130(Spec No 1): S43-52.

[5] Oberholzer C, Nüesch R, Häusermann P. Urticaria and parasites: case report and general view over the most common pathogens of chronic urticaria. Praxis (Bern 1994) 2007; 96(21): 865-70.

[6] Clyne CA, Eliopoulos GM. Fever and urticaria in acute giardiasis. Arch Intern Med 1989; 149(4): 939-40.

[7] Nenoff P, Domula E, Willing U, Herrmann J. Giardia lamblia-cause of urticaria and pruritus or accidental association? Hautarzt 2006; 57(6): 518-20.

[8] Micheloud D, Jensen J, Fernandez-Cruz E, Carbone J. Chronic angioedema and blastocystis hominis infection. Rev Gastroenterol Peru 2007; 27(2): 191-3

[9] Pasqui AL, Savini E, Saletti M, Guzzo C, Puccetti L, Auteri A. Chronic urticaria and blastocystis hominis infection: a case report. Eur Rev Med Pharmacol Sci 2004; 8(3): 117-20.

[10] Lynch NR, Hagel IA, Palenque ME, et al. Relationship between helminthic infection and IgE response in atopic and nonatopic children in a tropical environment. J Allergy Clin Immunol 1998; 101: 217-21.

[11] Moreau E, Chauvin A. Immunity against Helminths: Interactions with the host and the intercurrent infections. J Biomed Biotechnol 2010; 2010: Article ID 428593, doi:10.1155/2010/428593.

[12] Figueiredo CA, Barreto ML, Rodrigues LC, et al. Chronic intestinal helminth infections are associated with immune hyporesponsiveness and induction of a regulatory network. Infect Immunity 2010; 78(7): 3160-7.

[13] Maizels RM. Infections and allergy —-helminths, hygiene and host immune regulation. Curr Opinion Immunol 2005; 17(6): 656-61.

[14] Mingomataj EÇ, Xhixha F, Gjata E. Helminthes can protect themselves against rejection inhibiting hostile respiratory allergy symptoms. Allergy 2006; 61(4): 400-6.

[15] Buijs J, Egbers MW, Lokhorst WH, Savelkoul HF, Nijkamp FP. Toxocara-induced eosinophilic inflammation. Airway function and effects of anti-IL-5. Am J Respir Crit Care Med 1995; 151(3 Pt 1): 873-8.

[16] Wang CC, Nolan TJ, Schad GA, Abraham D. Infection in mice with the helminth Strongyloides stercoralis suppresses pulmonary allergic responses to ovalbumin. Clin Exp Allergy 2001; 31: 495503.

[17] Dzik JM. Molecules released by helminth parasites involved in host colonization. Acta Biochimica Polonica 2006; 53(1): 33-64.

[18] De Macedo Soares MF, Mahasti Sahihi de Macedo MS. Modulation of Anaphylaxis by Helminth-derived Products in Animal Models. Curr Allergy Asthma Reports 2007; 7: 56-61. 
[19] Paterson S, Wilkes CP, Bleay C, Viney ME. Immunological responses elicited by different infection regimes with Strongyloides ratti. PLoS ONE 2008; 3(6): e2509.

[20] Bleay C, Wilkes CP, Paterson S, Viney ME. Density-dependent immune responses against the gastrointestinal nematode Strongyloides ratti. Int J Parasitol 2007; 37(13): 1501-9.

[21] Vuitton DA. The ambiguous role of immunity in echinococcosis: protection of the host or of the parasite? Acta Trop 2003; 85(2): 119-32.

[22] Caldas IR, Campi-Azevedo AC, Oliveira LF, Silveira AM, Gazzinelli G. Human schistosomiasis mansoni: immune responses during acute and chronic phases of the infection. Acta Trop 2008; 108(2-3): 109-17.

[23] Correa-Oliveira R, Malaquais LC, Falcao PL, et al. Cytokines as determinants of resistance and pathology in human Schistosoma mansoni infection. Braz J Med Biol Res 1998; 31(1): 171-7.

[24] Djamiatun K, Faubert GM. Exogenous cytokines released by spleen and Peyer's patch cells removed from mice infected with Giardia muris. Parasite Immunol 1998; 20(1): 27-36.

[25] Adjobimey T, Hoerauf A. Induction of immunoglobulin G4 in human filariasis: an indicator of immunoregulation. Ann Trop Med Parasitol 2010; 104(6): 455-64.

[26] Ghosh K, Ghosh K. Strongyloides stercoralis septicaemia following steroid therapy for eosinophilia: report of three cases. Trans $\mathrm{R}$ Soc Trop Med Hyg 2007; 101(11): 1163-5.

[27] Brehm K, Spiliotis M. The influence of host hormones and cytokines on Echinococcus multilocularis signalling and development. Parasite 2008; 15(3): 286-90.

[28] Hübner MP, Pasche B, Kalaydjiev S, Soboslay PT, Lengeling A, Schulz-Key H, et al. Microfilariae of the filarial nematode Litomosoides sigmodontis exacerbate the course of lipopolysaccharideinduced sepsis in mice. Infect Immunol 2008; 76(4): 1668-77.

[29] Gottstein B, Piarroux R. Current trends in tissue-affecting helminths. Parasite 2008; 15(3): 291-8.

[30] Maizels RM, Balic A, Gomez-Escobar N, Nair M, Taylor MD, Allen JE. Helminth parasites - masters of regulation. Immunol Rev 2004; 201: 89-116.

[31] Vuitton DA. Echinococcosis and allergy. Clin Rev Allergy Immunol 2004; 26(2): 93-104.

[32] Cuellar C, Perteguer MJ, Roderom M. Presence of IL-4-like molecules in larval excretory-secretory products and crude extracts from Anisakis simplex. Scand J Immunol 2001; 53(5): 483-8.

[33] Shaio MF, Hou SC, Chen JG, Wu CC, Yang KD, Chang FY. Immunoglobulin G-dependent classical complement pathway activation in neutrophil-mediated cytotoxicity to infective larvae of Angiostrongylus cantonensis. Ann Trop Med Parasitol 1990; 84(2): $185-91$.

[34] Gadjeva MG, Rouseva MM, Zlatarova AS, Reid KB, Kishore U, Kojouharova MS. Interaction of human $\mathrm{C} 1 \mathrm{q}$ with $\mathrm{IgG}$ and $\mathrm{IgM}$ : revisited. Biochemistry 2008; 47(49): 13093-102.

[35] Garcia-Hernandez P, Rodero M, Cuellar C. Anisakis simplex: the activity of larval products on the complement system. Exp Parasitol 2007; 115(1): 1-8

[36] Garcia-Hernandez P, Rodero M, Cuellar C. Study of the effect of Anisakis simplex larval products on the early and late components in the classical complement pathway. J Parasitol 2009; 95(1): 240-1.

[37] Torres VM. Dermatologic manifestations of Schistosomiasis mansoni. Arch Dermatol 1976; 112: 1539-42.

[38] Bruschi F. The significance of the "lung phase" in host-helminth relations. Parassitologia 1992; 34(1-3): 23-30.

[39] Magnaval JF, Faufingue JH, Morassin B, Fabre R. Eosinophil cationic protein, specific $\mathrm{IgE}$ and $\mathrm{IgG} 4$ in human toxocariasis. $\mathrm{J}$ Helminthol 2006; 80(4): 417-23.

[40] Cooper PJ. Intestinal worms and human allergy. Parasite Immunol 2004; 26(11-12): 455-67.

[41] Mulcahy G, O'Neill S, Fanning J, McCarthy E, Sekiya M. Tissue migration by parasitic helminths - an immunoevasive strategy? Trends Parasitol 2005; 21: 273-7

[42] Sastre J, Lluch-Bernal M, Quirce S, et al. A double-blind, placebocontrolled oral challenge study with lyophilized larvae and antigen of the fish parasite, Anisakis simplex. Allergy 2000; 55(6): 560-4.

[43] Daschner A, Alonso-Gomez A, Cabanas R, Suarez-de-Parga JM, Lopez-Serrano MC. Gastroallergic anisakiasis: borderline between food allergy and parasitic disease-clinical and allergologic evalua- tion of 20 patients with confirmed acute parasitism by Anisakis simplex. J Allergy Clin Immunol 2000; 105(1 Pt 1): 176-81.

[44] Sasmal NK, Acharya S, Laha R. Larval migration of Toxocara canis in piglets and transfer of larvae from infected porcine tissue to mice. J Helminthol 2008; 82(3): 245-9.

[45] Weiss ST. Parasites and asthma/allergy: what is the relationship? J Allergy Clin Immunol 2000; 105: 205-10.

[46] Von Allmen N, Bienz M, Hemphill A, Müller N. Experimental infections of neonatal mice with cysts of Giardia lamblia clone GS/M-83-H7 are associated with an antigenic reset of the parasite. Infect Immunol 2004; 72(8): 4763-71.

[47] Lacy P, Weller PF, Moqbel R. A report from the International Eosinophil Society: Eosinophils in a tug of war. J Allergy Clin Immunol 2001; 108: 895-900.

[48] Mingomataj EÇ. Eosinophil-induced prognosis improvement of solid tumors could be enabled by their vesicle-mediated barrier permeability induction. Med Hypotheses 2008; 70: 582-584.

[49] Egesten A, Calafat J, Janssen H, Knol EF, Malm J, Persson T. Granules of human eosinophilic leucocytes and their mobilization. Clin Exp Allergy 2001; 31: 1173-88.

[50] Kaji K, Yoshiji H, Yoshikawa M, et al. Eosinophilic cholecystitis along with pericarditis caused by Ascaris lumbricoides: A case report. World J Gastroenterol 2007; 13(27): 3760-2.

[51] Lee JD, Tsai LY, Chen CH, Wang JJ, Hsiao JK, Yen CM. Bloodbrain barrier dysfunction occurring in mice infected with Angiostrongylus cantonensis. Acta Trop 2006; 97: 204-11.

[52] Humbert P, Buchet S, Barde T. Toxocariasis. A cosmopolitan parasitic zoonosis. Allerg Immunol 1995; 27(8): 284-91.

[53] Petithory JC. Visceral and cutaneous larva migrans. Rev Prat 2007 57(18): 1977-83

[54] Lee JJ, Jacobsen EA, McGarry MP, Schleimer RP, Lee NA. Eosinophils in health and disease: the LIAR hypothesis. Clin Exp Allergy 2010; 40(4): 563-75.

[55] Stein LH, Redding KM, Lee JJ, et al. Eosinophils utilize multiple chemokine receptors for chemotaxis to the parasitic nematode Strongyloides stercoralis. J Innate Immun 2009; 1(6):618-30.

[56] Tanaka J, Torisu M. Anisakis and eosinophil. I. Detection of a soluble factor selectively chemotactic for eosinophils in the extract from Anisakis larvae. J Immunol 1978; 120(3): 745-9.

[57] Sanchez-Monsalvez I. de Armas-Serra C, Bernadina W, RodriguezCaabeiro F. Altered autonomic control in rat intestine due to both infection with Anisakis simplex and incubation with the parasite's crude extract. Dig Dis Sci 2003; 48(12): 234-52

[58] Cairncross S, Müller R, Zagaria N. Dracunculiasis (Guinea Worm Disease) and the eradication initiative. Clin Microbiol Rev 2002; 15(2): 223-46.

[59] Havlicek J, Gasova ZG, Smith AP, Zvara K, Flegr J. Decrease of psychomotor performance in subjects with latent "asymptomatic" toxoplasmosis. Parasitology 2001;122(5):515-20.

[60] Dobson AP. The population biology of parasite-induced changes in host behavior. Q Rev Biol 1988; 63(2): 139-65.

[61] Berdoy M, Webster JP, Macdonald DW. Fatal attraction in rats infected with Toxoplasma gondii. Proc Biol Sci 2000; 267(1452): $1591-4$

[62] Webster J. The Effect of Toxoplasma gondii on Animal Behavior: Playing Cat and Mouse. Schizophr Bull 2007; 33(3): 752-6.

[63] Ferreira da Silva Mda F, Barbosa HS, Gross U, Lüder CG. Stressrelated and spontaneous stage differentiation of Toxoplasma gondii. Mol Biosyst 2008; 4(8): 824-34.

[64] Gissot M, Kim K. How epigenomics contributes to the understanding of gene regulation in Toxoplasma gondii. J Eukaryot Microbiol 2008; 55(6): 476-80

[65] Gissot M, Kelly KA, Ajioka JW, Greally JM, Kim K. Epigenomic modifications predict active promoters and gene structure in Toxoplasma gondii. PLoS Pathol 2007; 3(6): e77.

[66] Smith JE. Tracking transmission of the zoonosis Toxoplasma gondii. Adv Parasitol 2009; 68: 139-59.

[67] Zimmer C. EVOLUTION: Parasites Make Scaredy-Rats Foolhardy. Science 2000; 289(5479): 525b-527b.

[68] Hamilton CM, Stafford P, Pinelli E, Holland CV. A murine model for cerebral toxocariasis: characterization of host susceptibility and behavior. Parasitol 2006; 132(Pt 6): 791-801.

[69] Cox DM, Holland CV. Relationship between three intensity levels of Toxocara canis larvae in the brain and effects on exploration, anxiety, learning and memory in the murine host. J Helminthol 2001; 75(1): 33-41. 
[70] Dittrich AM, Hamelmann E. [Parasites and allergies: from mice to men]. Allergo J 2009; 18(3): 190-5.

[71] Read AF, Skorping A. The evolution of tissue migration by parasitic nematode larvae. Parasitology 1995; 111(3): 359-7.

[72] Berdoy M, Webster JP, Macdonald DW. Parasite-altered behaviour: is the effect of Toxoplasma gondii on Rattus norvegicus specific? Parasitology 1995; 111(4): 403-9.

[73] Martin ES. Increase of mast cells in the peritoneal cavity of rats treated atopic patient's serum. Allergol Immunopathol (Madr) 1976; 4(2): 131-8.

[74] Gavignet B, Piarroux R, Aubin F, Millon L, Humbert P. Cutaneous manifestations of human toxocariasis. J Am Acad Dermatol 2008; 59(6): 1031-42.

[75] Gonzalez-Muñoz M, Rodriguez-Mahillo AI, Moneo I. Different Th1/Th2 responses to Anisakis simplex are related to distinct clinical manifestations in sensitized patients. Parasite Immunol 2010; 32(1): 67-73.
[76] Loschiavo F, Ventura-Spagnolo T, Di Bella P, Bramanti P. Urticarioid manifestation in course of cerebral imported malaria. Acta Neurol (Napoli) 1993; 15(3): 211-4.

[77] Mahmoud MS, Salem AA, Rifaat MM. Human giardiasis as an etiology of skin allergy: the role of adhesion molecules and interleukin-6. J Egypt Soc Parasitol 2004; 34(3): 723-37.

[78] Endara P, Vaca M, Chico ME, et al. Long-term periodic anthelmintic treatments are associated with increased allergen skin reactivity. Clin Exp Allergy 2010; 40(11): 1669-77.

[79] Flohr C, Tuyen LN, Quinnell RJ, et al. Reduced helminth burden increases allergen skin sensitization but not clinical allergy: a randomized, double-blind, placebo-controlled trial in Vietnam. Clin Exp Allergy 2010; 40(1): 131-42.

[80] Leiferman KM. A current perspective on the role of eosinophils in dermatologic diseases. J Am Acad Dermatol 1991; 24(6 Pt 2): 1101-12.

[81] Giacometti A, Cirioni O, Antonicelli L, et al. Prevalence of intestinal parasites among individuals with allergic skin diseases. J Parasitol 2003; 89(3): 490-2.

() Bakiri and Mingomataj; Licensee Bentham Open.

This is an open access article licensed under the terms of the Creative Commons Attribution Non-Commercial License (http://creativecommons.org/licenses/by-nc/3.0/) which permits unrestricted, non-commercial use, distribution and reproduction in any medium, provided the work is properly cited. 